\title{
Produção de novilhos de corte com suplementação em pastagem de azevém submetida a doses de nitrogênio ${ }^{1}$
}

\section{Gelson dos Santos Difante ${ }^{2}$, Enio Marchezan ${ }^{3}$, Silvio Carlos Cazarotto Villa ${ }^{5}$, Marta Gomes da Rocha $^{4}$, Fernando Machado dos Santos ${ }^{5}$, Edinalvo Rabaioli Camargo ${ }^{5}$}

\author{
${ }^{1}$ Parte da dissertação de Mestrado do primeiro autor. \\ 2 Doutor em Zootecnia. \\ ${ }^{3}$ Departamento de Fitotecnia, Universidade Federal de Santa Maria, UFSM. Santa Maria, RS, Campus, Camobi, CEP: $97119-900$. Bolsista \\ CNPq. \\ ${ }^{4}$ Departamento de Zootecnia, Universidade Federal de Santa Maria, UFSM. Santa Maria, RS, Campus, Camobi, CEP: $97119-900$. \\ 5 Graduação em Agronomia da UFSM.
}

RESUMO - O experimento foi realizado em várzea sistematizada com o objetivo de comparar os efeitos do uso de doses de $\mathrm{N}$ em cobertura, associadas a níveis de suplementação energética, sobre o desempenho animal e a qualidade e produção de forragem. Os tratamentos foram: $300 \mathrm{~N}+0,8 \mathrm{~S}$ = adubação com $300 \mathrm{~kg}$ de N/ha + suplementação com grão de milho moído $(0,8 \%$ do PV/dia); $200 \mathrm{~N}+0,4 \mathrm{~S}$ = adubação com $200 \mathrm{~kg}$ de N/ha + suplementação com grão de milho moído $(0,4 \%$ do PV/dia); e $100 \mathrm{~N}=$ adubação com $100 \mathrm{~kg}$ de N/ha, sem suplementação. Foram utilizados novilhos de corte da raça Charolês e suas cruzas com Nelore com idade inicial de 8 a 10 meses. A pastagem foi manejada sob lotação contínua e carga variável, no período de 15/07 a 03/11/2000, totalizando 110 dias de utilização. O teor de PB, a digestibilidade in vitro da MO (DIVMO) e a oferta de forragem (OF) foram maiores no início do período de pastejo e apenas a OF diferiu entre os tratamentos. As doses de $\mathrm{N}$ em cobertura, associadas a níveis de suplementação energética em pastagem de azevém, não alteraram o ganho médio diário dos animais, mas resultaram em maior carga animal e maior ganho de peso vivo por hectare.

Palavras-chave: arroz/pecuária, azevém, desempenho animal, pastagem cultivada, uréia

\section{Supplementation of beef steers on ryegrass pastures submitted to different nitrogen fertilization}

\begin{abstract}
The experiment was carried out in a leveled lowland area cultivated with Italian ryegrass (Lolium multiflorum Lam.). The objective was to compare the effect of nitrogen (N) and different energy supplementation levels on the following parameters: herbage quality, herbage yield, and animal production. The treatments were: $300 \mathrm{~N}+0.8 \mathrm{~S}-$ Italian ryegrass pasture plus $300 \mathrm{~kg} \cdot \mathrm{ha}^{-1}$ of $\mathrm{N}$ and supplementation with ground corn $(0.8 \% \mathrm{LW} / \mathrm{day}), 200 \mathrm{~N}+0.4 \mathrm{~S}-$ Italian ryegrass pasture plus $200 \mathrm{~kg} \cdot \mathrm{ha}^{-1}$ of $\mathrm{N}$ and supplementation with ground corn $(0.4 \% \mathrm{LW} /$ day $)$ and $100 \mathrm{~N}$ - Italian ryegrass pasture plus $100 \mathrm{~kg} \cdot \mathrm{ha}^{-1}$ of $\mathrm{N}$ without supplementation. Beef steers averaging eight to ten months old were used in the beginning of the experiment and allotted to continuous stocking with fixed stocking rate. Crude protein concentration, in vitro organic matter digestibility and forage on offer were greater in the beginning of the grazing period. Difference among treatments was observed only for forage on offer. Nitrogen levels, associated to different energy supplementation levels, did not affect average daily live weight gain, but resulted in greater stocking rate and, consequently, higher live weight gain/ha.
\end{abstract}

Key Words: rice/beef cattle, ryegrass, animal performance, planted pasture, urea

\section{Introdução}

No Rio Grande do Sul, há 5.994.600 ha de terras baixas, equivalentes a $20,5 \%$ da área total do estado, dos quais cerca de 900.000 ha são ocupados com a cultura do arroz irrigado, principalmente no sistema monocultura-pousio (Reis, 1998). O restante das áreas de várzea é utilizado para pecuária de corte, com baixos índices de produtividade. Entretanto, as áreas cultivadas com arroz são, normalmente, utilizadas em conjunto com a pecuária apenas no período de entressafra ou em sistema de rotação, com um ano de produção de arroz em sistema de irrigação para três ou quatro anos de pecuária. Sistemas integrados cultura de arroz x pastagens podem assegurar sua sustentabilidade e propiciar a oferta de forragem para os bovinos durante o período outono/inverno.

Saibro \& Silva (1999) destacaram a natureza complementar dos sistemas de produção integrados, em termos de 
maior reciclagem de nutrientes, por excrementos dos animais, de consorciação com leguminosas ou de incorporação dos restos das culturas, resultando em incremento no rendimento do arroz.

A utilização da adubação nitrogenada em pastagem cultivada pode ser um recurso para o incremento na produção de matéria seca, proporcionando aumento na produção animal, por meio da elevação da capacidade de suporte da pastagem e da produção animal por hectare (Blaser, 1964).

Entre as práticas de alimentação mais intensivas, a suplementação é a de mais fácil adoção pelo produtor, em virtude de seu menor custo de implantação. Em anos nos quais o preço do grão é atrativo, esta técnica pode ser utilizada em grande escala (Pascoal et al., 1999). A suplementação alimentar a campo é uma prática que pode ser encarada como medida de segurança para a continuidade da oferta de alimento em condições de deficit forrageiro, bem como o aumento da produção em situações normais, a manutenção de lotação alta durante o ciclo produtivo e a redução da variação da renda anual ou, até mesmo, o aumento dessa renda, dependendo do custo e da efetividade do alimento (Santini \& Elizalde, 1993; Rocha, 1999).

O desenvolvimento de alternativas viáveis de recria e terminação de bovinos nessas áreas contribui para a melhoria dos atuais sistemas integrados de exploração pecuária em rotação com arroz irrigado. Aumento da produção de carne, diminuição da idade de abate e manutenção da lotação podem ser atingidos em sistemas de alimentação com uso de pastagens cultivadas e suplementos energéticos.

Este trabalho foi conduzido com o objetivo de avaliar o uso de adubação de cobertura com diferentes doses de nitrogênio (N), em pastagem de azevém (Lolium multiflorum Lam.), associadas a níveis de suplementação energética, para a produção animal em área de várzea.

\section{Material e Métodos}

O experimento foi conduzido no ano de 2000 , em área de várzea sistematizada do campo experimental do Departamento de Fitotecnia da Universidade Federal de Santa Maria, em solo classificado como Planossolo Hidromórfico eutrófico arênico (EMBRAPA, 1999).

O clima da região é $\mathrm{Cfa}$ (subtropical úmido), conforme classificação de Köppen. As observações meteorológicas dos períodos experimentais (Figura 1) foram obtidas na Estação de Meteorologia do Departamento de Fitotecnia da UFSM, situada próximo à área experimental.

A implantação da pastagem foi realizada no dia 07/04/ 2000, quando foram semeados a lanço na área experimental $40 \mathrm{~kg} / \mathrm{ha}$ de sementes de azevém, sobre a vegetação previa-

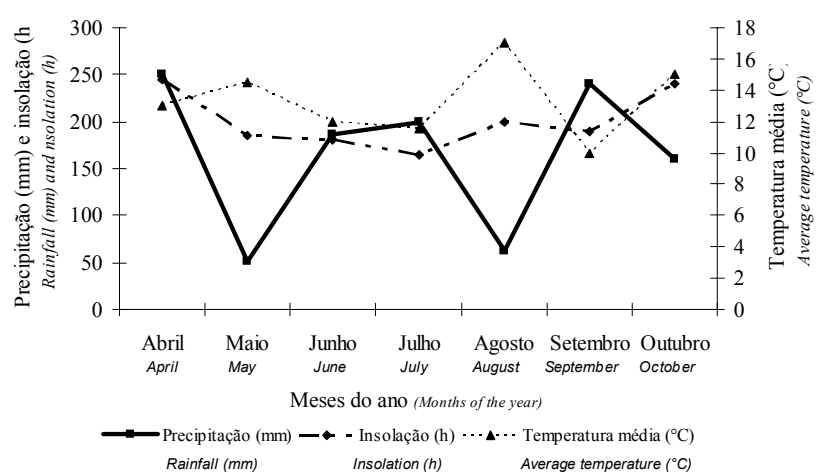

Figura 1 - Temperatura média $\left({ }^{\circ} \mathrm{C}\right)$, precipitação $(\mathrm{mm})$ e insolação (horas) mensais no período de utilização da pastagem de azevém.

Figure 1 - Monthly average temperature $\left({ }^{\circ} \mathrm{C}\right)$, rainfall $(\mathrm{mm})$ and insolation (hours) on utilization period of Italian ryegrass pasture submitted to nitrogen doses in continuous stocking rate with beef steers receiving energetic supplementation levels.

mente dessecada com dose de $1,8 \mathrm{~L} /$ ha do ingrediente ativo glifosate e $0,5 \%$ de óleo mineral. No dia 11/05/2000, foi ressemeado o azevém utilizando-se $25 \mathrm{~kg} /$ ha de sementes, em razão da baixa população de plantas. A área experimental era formada por três hectares, divididos em seis piquetes de $0,5 \mathrm{ha}$, que representavam cada unidade experimental.

Os tratamentos utilizados foram: $300 \mathrm{~N}+0,8 \mathrm{~S}=$ adubação com $300 \mathrm{~kg}$ de N/ha e suplementação com milho moído ( $0,8 \%$ do $\mathrm{PV} /$ dia); $200 \mathrm{~N}+0,4 \mathrm{~S}$ = adubação com $200 \mathrm{~kg}$ de N/ha e suplementação com milho moído $(0,4 \%$ do PV/dia); e $100 \mathrm{~N}$ = adubação com $100 \mathrm{~kg}$ de N/ha, sem suplementação.

A adubação de base foi realizada a lanço, após a emergência do azevém, nas doses recomendadas pela Comissão de Fertilidade do solo - RS/SC (1999), de acordo com as análises químicas do solo, feitas em amostras coletadas a $0-10 \mathrm{~cm}$ de profundidade, que apresentaram os seguintes resultados: $\mathrm{pHem} \mathrm{H}_{2} \mathrm{O}=6,0, \mathrm{Al}^{+++}=0,0 \mathrm{cmol} / \mathrm{dm}^{3}$, $\mathrm{Ca}^{++}=7,6 \mathrm{cmol} / \mathrm{dm}^{3}, \mathrm{Mg}^{++}=4,7 \mathrm{cmol} / \mathrm{dm}^{3}, \mathrm{CTC}=11,5 \mathrm{cmol} / \mathrm{dm}^{3}$, $\mathrm{K}^{+}=50,3 \mathrm{mg} / \mathrm{dm}^{3}, \mathrm{P}=10,5 \mathrm{mg} / \mathrm{dm}^{3} \mathrm{e} \mathrm{MO}=2,2 \%$. A adubação nitrogenada foi aplicada em cobertura, a lanço, na forma de uréia, dividida em cinco aplicações, nas seguintes datas: 01/06, 07/07, 28/07, 02/09 e 07/10/2000.

A disponibilidade de forragem da pastagem foi avaliada por meio da técnica de dupla amostragem (Wilm, 1944), com determinações realizadas a cada 28 dias, por meio da coleta de cinco amostras de $0,25 \mathrm{~m}^{2}$ e da estimativa visual de 25 amostras por unidade experimental. A forragem proveniente das amostras foi homogeneizada e parte foi utilizada para determinação do teor de MS após secagem em estufa de circulação forçada a $65^{\circ} \mathrm{C}$.

A taxa de acúmulo diário de matéria seca (TAMS) foi determinada utilizando-se a técnica do triplo emparelhamento 
(Moraes et al., 1990). As avaliações foram realizadas a cada 28 dias com o uso de três gaiolas de exclusão por unidade experimental.

A oferta de forragem( $(\mathrm{OF})$, em $\mathrm{kg}$ de $\mathrm{MS} / 100 \mathrm{~kg}$ de $\mathrm{PV} / \mathrm{dia}$, foi obtida pela divisão da quantidade de forragem disponível no período pelo número de dias do período, acrescida do valor da taxa de acúmulo diário de MS/ha. Esse valor corresponde à quantidade de MS disponível para a taxa de lotação utilizada sobre a área; ajustando para 100, obteve-se a oferta de forragem para cada $100 \mathrm{~kg}$ de PV.

Os parâmetros qualitativos foram estimados a partir de amostras da forragem semelhantes à aparentemente consumida, coletadas em intervalos de 28 dias, por dois avaliadores treinados, em cada unidade experimental, por meio da técnica de simulação do pastejo (Euclides et al., 1992). As amostras foram secas em estufa a $65^{\circ} \mathrm{C}$, processadas em moinho tipo Willey com peneira de $1 \mathrm{~mm}$ e analisadas quanto aos teores de $\mathrm{PB}$, conforme recomendações da AOAC (1984), e a DIVMO, determinada pelo método proposto por Tilley \& Terry (1963).

Foram utilizados bovinos machos castrados da raça Charolês e suas cruzas com Nelore, com idade média de 8 a 10 meses e peso médio inicial de $168 \mathrm{~kg}$. Os animais foram distribuídos nos tratamentos, mantendo-se 6 animais/ha nos tratamentos $300 \mathrm{~N}+0,8 \mathrm{~S}$ e $200 \mathrm{~N}+0,4 \mathrm{~S}$ e 4 animais/ha no tratamento $100 \mathrm{~N}$. Foi utilizada lotação contínua com carga animal variável, de acordo com o aumento de peso dos animais durante o período experimental. Para adaptação à nova dieta e ao manejo, os animais passaram por um período de adaptação de 12 dias em pastagem semelhante à utilizada no experimento, com suplementação diária. O período de pastejo foi de $15 / 07$ a 03/11/2000, totalizando 110 dias.

O suplemento (grão de milho moído) foi fornecido diariamente (13h) na proporção de 0,8 e $0,4 \%$ do PV, para os tratamentos $300 \mathrm{~N}+0,8 \mathrm{~S}$ e $200 \mathrm{~N}+0,4 \mathrm{~S}$, respectivamente. A oferta do suplemento foi feita em um cocho de madeira $(1,5 \times 0,4 \times 0,2 \mathrm{~m})$ por piquete, em quantidade ajustada semanalmente, de acordo com a estimativa do ganho de peso dos animais, com base no ganho médio diário do período anterior. Para determinação do consumo do suplemento, foram coletadas e pesadas as sobras deixadas pelos animais. Após o ajuste da quantidade de suplemento ofertada, de sobras coletadas nos cochos e do ganho de peso real do período, foram determinados os consumos reais de 0,8 e $0,4 \%$ do PV para os tratamentos com suplementação.

A pesagem dos animais foi feita no início do experimento e, partir desta data, em intervalos de 28 dias até o final do experimento. Em todas as pesagens, os animais foram submetidos a jejum prévio de 6 horas. Foram determinados o ganho médio diário (GMD), o ganho de PV por hectare (GPV) e a carga animal (CA). O GMD foi obtido pela diferença de peso entre as pesagens realizadas no início e ao final de cada período experimental, dividido pelo número de dias do intervalo. O GPV foi calculado pelo produto do ganho de peso médio por animal no período pelo número de animais por hectare e a CA, pelo somatório do peso dos animais de cada unidade experimental, após correção para hectare.

O delineamento experimental foi o inteiramente casualizado, com duas repetições de área, em arranjo fatorial $3 \times 4$, em que os três tratamentos foram $300 \mathrm{~N}+0,8 \mathrm{~S}, 200 \mathrm{~N}+0,4 \mathrm{~S}$ e $100 \mathrm{~N}$ e os quatro períodos consistiram das avaliações realizadas aos 28 (15/07-11/08), 56(12/08-08/09), 84 (09/0906/10) e $112(07 / 10-03 / 11)$ dias. Os parâmetros avaliados foram submetidos à análise de variância por meio do General Linear Models Procedure (Proc GLM) e as diferenças entre tratamentos foram comparadas pelo teste Tukey $(\mathrm{P} \leq 0,05)$. Foi utilizado o pacote estatístico SAS versão 6.08 (1990). O modelo matemático foi:

$$
\mathrm{Y}_{\mathrm{ijk}}=\mu+\mathrm{T}_{\mathrm{i}}+\mathrm{P}_{\mathrm{j}}+(\mathrm{TP})_{\mathrm{ij}}+\varepsilon_{\mathrm{ijk}}
$$

em que $Y_{i j k}=$ variáveis dependentes; $\mu=$ média de todas as observações; $\mathrm{T}_{\mathrm{i}}=$ efeito de tratamento, $\mathrm{i}=1,2$ e $3 ; \mathrm{P}_{\mathrm{j}}=$ efeito do j-ésimo dos períodos de 28, 56, 84 e 112 dias; $(\mathrm{TP})_{\mathrm{ij}}=$ interação i-ésimo tratamento $\times$ j-ésimo período; $\varepsilon_{\mathrm{ijk}}=$ erro experimental residual (erro b).

\section{Resultados e Discussão}

O teor de $\mathrm{PB}$ na simulação de pastejo (Tabela 1) não diferiu significativamente entre os tratamentos $(\mathrm{P}>0,05)$, apresentando média de $14,5 \%$, contrariando os dados encontrados por Lupatini et al. (1998), que observaram aumento linear de 13,17 a 22,24\% no teor de PB na mistura de aveia preta e azevém, utilizando 0 a $300 \mathrm{~kg} / \mathrm{ha}$ de $\mathrm{N}$, respectivamente. Estes dados conduzem à hipótese de que o excesso de precipitação durante o período experimental (Figura 1) pode ter provocado perda de parte do nitrogênio aplicado.

Entre os períodos, observou-se que a porcentagem de PB foi superior $(\mathrm{P}<0,05)$ no início do período de pastejo, o que está de acordo com os resultados obtidos por Lupatini et al. (1998), utilizando mistura de aveia preta e azevém, e Roso et al. (1999), em pastagem de azevém. O maior valor de PB observado no primeiro período provavelmente está relacionado ao aproveitamento das aplicações de nitrogênio realizadas no mês de julho, em razão das melhores condições de precipitação verificadas neste mês (Figura 1).

Os valores de DIVMO da simulação de pastejo não diferiram significativamente $(\mathrm{P}>0,05)$ entre os tratamentos. Verificaram-se maiores valores de digestibilidade no início da utilização da pastagem, resultantes do pleno crescimento 
Tabela 1 - Teor de PB (\%) e digestibilidade in vitro da MO (\%) da simulação de pastejo de pastagens de azevém submetidas a doses de nitrogênio sob lotação contínua com bovinos de corte recebendo suplementação energética

Table 1 - $\quad C P$ concentration (\%CP) and "in vitro" OM digestibility (\%IVOMD) of hand-plucked samples of ryegrass pasture fertilized with different nitrogen levels and grazed by beef steers fed diets with levels of energy supplementation, under a continuous stocking rate

\begin{tabular}{|c|c|c|c|c|c|}
\hline \multirow[t]{2}{*}{$\begin{array}{l}\text { Nível } \\
\text { Level }\end{array}$} & \multicolumn{4}{|c|}{$\begin{array}{l}\text { Período } \\
\text { Period }\end{array}$} & \multirow[t]{2}{*}{$\begin{array}{l}\text { Média } \\
\text { Mean }\end{array}$} \\
\hline & $15 / 07-11 / 08$ & $12 / 08-08 / 09$ & $09 / 09-06 / 10$ & $07 / 10-03 / 11$ & \\
\hline $300 \mathrm{~N}+0,8 \mathrm{~S}$ & 23,8 & 14,9 & 14,8 & 8,5 & $15,5^{\text {ns }}$ \\
\hline $200 N+0,4 S$ & 23,1 & 13,6 & 13,4 & 10,5 & 15,2 \\
\hline $100 \mathrm{~N}$ & 18,2 & 11,2 & 11,6 & 10,5 & 12,9 \\
\hline \multicolumn{6}{|c|}{ \%DIVMO (\%IVOMD) } \\
\hline $300 \mathrm{~N}+0,8 \mathrm{~S}$ & 73,0 & 42,8 & 50,6 & 40,3 & $51,7 \mathrm{~ns}$ \\
\hline $200 \mathrm{~N}+0,4 \mathrm{~S}$ & 73,7 & 53,6 & 44,2 & 40,9 & 53,1 \\
\hline $100 \mathrm{~N}$ & 70,5 & 56,2 & 52,6 & 41,6 & 55,2 \\
\hline Média (Mean) & $72,4 \mathrm{~A}$ & $50,9 \mathrm{~B}$ & $49,1 \mathrm{~B}$ & $40,9 \mathrm{C}$ & 53,3 \\
\hline
\end{tabular}

* Médias seguidas de letras diferentes maiúsculas na linha e minúsculas na coluna diferem $(P<0,05)$ entre si pelo teste Tukey.

ns não-significativo a $5 \%$ de probabilidade pelo Teste $F$.

* Means followed by different capital letters in a row and small letters in a column differ $(P<0.05)$ by Tukey test.

ns F test not significant at $5 \%$ level.

vegetativo do azevém. A menor digestibilidade observada no último período coincidiu com o final do ciclo de produção do azevém e com o maior percentual de material morto observado na composição botânica da pastagem. Esse mesmo comportamento foi observado por Canto et al. (1997), Restle et al. (1998), Roso et al. (1999) e Restle et al. (2000), em gramíneas de estação fria.

Na Tabela 2 são apresentados os valores de massa de forragem e OF da pastagem de azevém submetida a doses de nitrogênio sob lotação contínua com bovinos de corte recebendo suplementação energética. $O$ tratamento $300 \mathrm{~N}+0,8 \mathrm{~S}$ apresentou maior massa de forragem $(\mathrm{P}<0,05)$, possivelmente em virtude da maior quantidade de nitrogênio aplicada e do fornecimento do maior nível de suplemento ( $0,8 \%$ do PV), o que ocasionou substituição da pastagem pelo suplemento. Os tratamentos $200 \mathrm{~N}+0,4 \mathrm{~S}$ e $100 \mathrm{~N}$ apresentaram massa de forragem semelhante; $0200 \mathrm{~N}+0,4 \mathrm{~S}$ apresentou menor taxa de substituição, em virtude do menor nível de suplementação utilizado ( $0,4 \%$ do PV), em comparação ao $300 \mathrm{~N}+0,8 \mathrm{~S}$.

A OF foi diferente para tratamentos e períodos $(\mathrm{P}<0,05)$, observando-se o maior valor no tratamento $100 \mathrm{~N}$, em razão da menor taxa de lotação utilizada, não diferindo do tratamento $300 \mathrm{~N}+0,8 \mathrm{~S}$. Este tratamento, apesar de não apresentar lotação mais elevada, manteve-se com maior oferta, em razão do nível mais alto de suplemento, que substituiu o consumo da forragem, e da maior dose de nitrogênio. Por outro lado, o tratamento $300 \mathrm{~N}+0,8 \mathrm{~S}$ não diferiu do $200 \mathrm{~N}+0,4 \mathrm{~S}$, que apresentou o mesmo efeito substitutivo, em menor proporção.
No primeiro período de utilização da pastagem, houve grande quantidade de MS ofertada $(13,2)$, semelhante ao segundo período $(10,0)$. Com o aumento progressivo da CA, resultante do ganho de peso dos animais, houve redução na $\mathrm{OF}$ a partir do terceiro período, agravando-se no último período avaliado, que coincidiu com a maior carga animal utilizada e com o final do ciclo de desenvolvimento do azevém, limitando o consumo e, conseqüentemente, o ganho de peso dos animais. Segundo Gibb \& Treacher (1976), ruminantes em pastejo necessitam de OF três vezes e meia maior que seu consumo voluntário máximo.

A utilização de lotação fixa não permitiu ajustes nas taxas de lotação nos tratamentos para manter o mesmo nível de OF durante o período de utilização da pastagem. Segundo Silva et al. (1997), OF de $10 \mathrm{~kg}$ de MS/100 kg de PV/dia em pastagens desta natureza permite a obtenção de bons rendimentos por área e adequados desempenhos individuais. No segundo período avaliado (12/08 a 08/09), este nível de oferta foi mantido, sendo observados os maiores ganhos médios diários e, conseqüentemente, o maior ganho por área, confirmando que este nível de OF é adequado para pastagens de azevém.

Na Tabela 3 são apresentados os valores de GMD, de CA e GPV. Não houve diferença no GMD entre os tratamentos testados $(\mathrm{P}>0,05)$, comprovando ausência de efeito aditivo do suplemento na dieta dos animais e que a utilização exclusiva da pastagem de azevém pode suprir as necessidades energéticas dos novilhos, permitindo ganhos semelhantes ao dos animais sob suplementação. 
Tabela 2 - Massa de forragem (MF, kg/ha de MS) e oferta de forragem (OF, kg MS/100 kg PV) em pastagem de azevém submetida a doses de nitrogênio sob lotação contínua com bovinos de corte recebendo suplementação energética

Table 2 - Herbage mass (HM, kg/ha DM) and forage on offer (FO, $\mathrm{kg} D M / 100 \mathrm{~kg} L W$ ) of ryegrass pastures fertilized with different nitrogen levels and grazed by beef steers fed diets with different levels of energy supplementation, under a continuous stocking rate

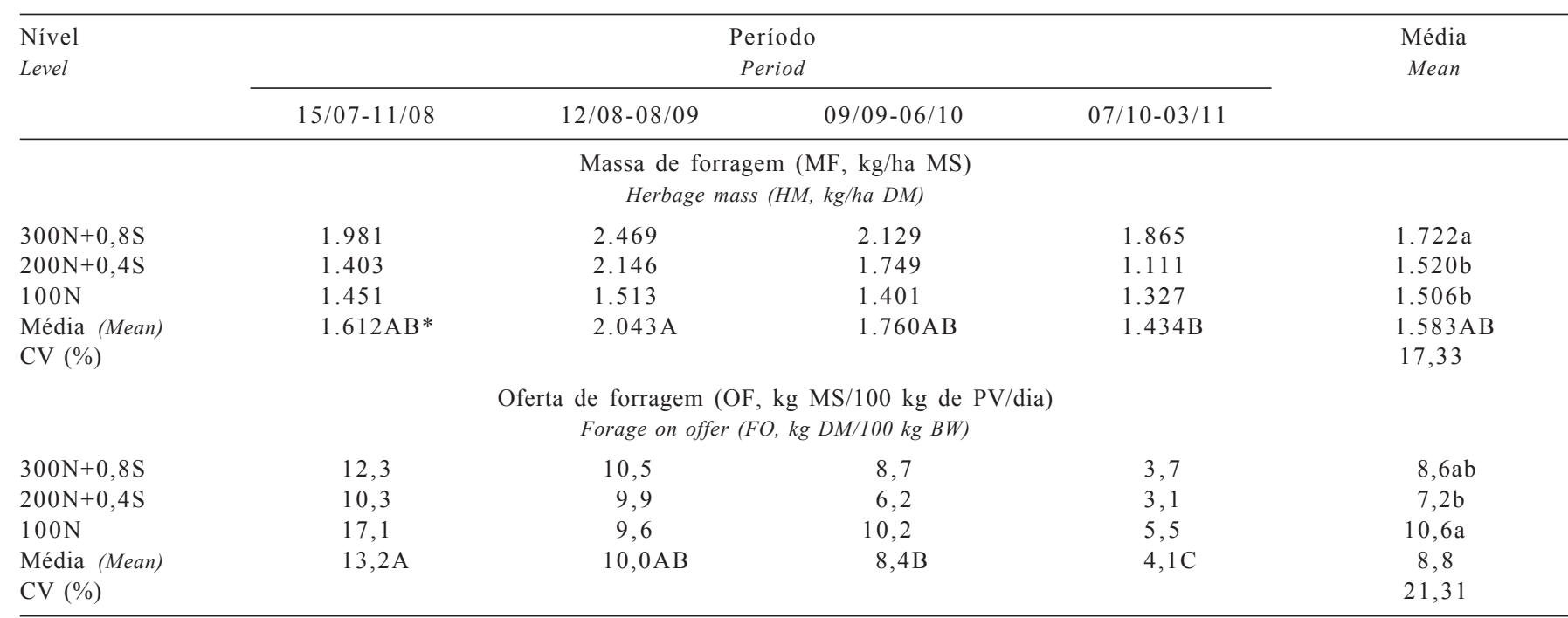

* Médias seguidas de letras diferentes maiúsculas na linha e minúsculas na coluna diferem $(P<0,05)$ entre si pelo teste Tukey.

* Means followed by different capital letters in a row and small letters in a column differ $(P<.05)$ by Tukey test.

Tabela 3 - Ganho de peso médio diário (GMD, g/animal/dia), carga animal (CA, kg/ha) e ganho de peso vivo por hectare (GPV, kg/ha) em pastagens de azevém adubadas com nitrogênio e pastejadas sob lotação contínua por bovinos de corte recebendo suplementação energética

Table 3 - $\quad$ Average daily live weight gain (ADG, g/animal/day), stocking rate ( $\mathrm{kg}$ of $L W /$ ha) and live weight gain (LWG) in ryegrass pastures fertilized with different nitrogen levels and grazed by beef steers fed diets with different levels of energy supplementation, under a continuous stocking rate

\begin{tabular}{|c|c|c|c|c|c|c|}
\hline \multirow{3}{*}{$\begin{array}{l}\text { Nível } \\
\text { Level }\end{array}$} & \multicolumn{5}{|c|}{ Período } & \multirow{3}{*}{$\begin{array}{l}\text { Média } \\
\text { Mean }\end{array}$} \\
\hline & \multicolumn{5}{|c|}{ Period } & \\
\hline & $15 / 07$ & $15 / 07-11 / 08$ & $12 / 08-08 / 09$ & $09 / 09-06 / 10$ & $07 / 10-03 / 11$ & \\
\hline
\end{tabular}

Ganho médio diário (GMD, g/animal/dia)

Average daily live weight gain (ADG, g/day)

\section{$300 \mathrm{~N}+0,8 \mathrm{~S}$ \\ $200 \mathrm{~N}+0,4 \mathrm{~S}$ \\ $100 \mathrm{~N}$ \\ Média (Mean) \\ CV (\%)}

$\begin{array}{lcc}300 \mathrm{~N}+0,8 \mathrm{~S} & 1.017,5 & 1.188,0 \\ 200 \mathrm{~N}+0,4 \mathrm{~S} & 1.012,0 & 1.192,0 \\ 100 \mathrm{~N} & 660,0 & 794,5 \\ \text { Média (Mean) } & 896,5 \mathrm{E} & 1.058,2 \mathrm{D}\end{array}$

$896,5 \mathrm{E}$

$$
\begin{aligned}
& 1.470 \\
& 1.395 \\
& 1.419
\end{aligned}
$$$$
1.428 \mathrm{~A}
$$

\section{9}

639

889

$762 \mathrm{C}$

1.236

$1.294 \mathrm{AB}$

762

Carga animal (CA, kg/ha de PV) Stocking rate (SR, $\mathrm{kg} / \mathrm{ha}$ )

CV (\%)

$$
\begin{gathered}
1.435,0 \\
1.426,5 \\
953,5 \\
1.271,6 \mathrm{C}
\end{gathered}
$$

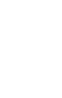


Observou-se menor GMD no primeiro período $(\mathrm{P}<0,05)$, em comparação ao segundo, decorrente do processo de adaptação dos animais à nova área, apesar de a qualidade da forragem ofertada no início do pastejo ter sido maior. O menor GMD observado no último período foi conseqüência da menor OF e de sua baixa qualidade, limitando o consumo e não suprindo as exigências nutricionais para maior ganho de peso. Comportamento semelhante foi observado por Restle et al. (1998), ao avaliarem diferentes categorias de bovinos de corte em pastagem cultivada. Esses autores observaram que a redução da qualidade da pastagem coincide com o aumento das exigências nutricionais dos animais, principalmente de energia.

A CA média apresentou diferença significativa entre os tratamentos com e sem suplementação $(\mathrm{P}<0,05)$, demonstrando o efeito substitutivo do consumo de forragem por suplemento, o que permitiu maior capacidade de suporte na pastagem. O valor observado para este parâmetro foi inferior ao obtido por Restle et al. (1998), com a mesma categoria animal, em pastagem de aveia e azevém com lotação variável. A taxa de lotação nos tratamentos com suplementação foi mantida em seis novilhos/ha e, no tratamento com suplementação, em quatro animais/ha com PV médio de 234,6 kg.

Incremento da CA entre os períodos avaliados resultou do ganho de peso dos animais, pois foi utilizada lotação fixa durante o período experimental. A CA média no tratamento sem suplementação foi de $937,6 \mathrm{~kg} / \mathrm{ha}$, inferior à encontrada por Marchezan et al. (2000), de $1.017 \mathrm{~kg} / \mathrm{ha}$, na mesma área e com a mesma categoria animal, porém com $22,91 \%$ de azevém e $26,85 \%$ de trevo branco na composição botânica média da pastagem. A suplementação, associada às maiores doses de N, permitiu utilizar taxa de lotação $50,4 \%$ superior àquela utilizada no tratamento sem suplementação e com menor dose de N. Rocha et al. (2000) verificaram incrementos de 58 e $39 \%$ na taxa de lotação para os tratamentos com suplementação energética a 1,28 e 1,02\% do PV/dia, respectivamente, em pastagem cultivada. Frizzo et al. (2003) obtiveram aumento de $26 \%$ na taxa de lotação para os níveis de suplementação de $0,7 \%$ e de $73 \%$ do PV/dia para o nível de $1,4 \%$ do $\mathrm{PV} /$ dia, quando comparados ao tratamento sem suplementação em pastagem cultivada.

O GPV foi maior nos tratamentos com suplementação, com produções totais de 763,5; 722,0 e 527,0 kg/ha de PV para os tratamentos $300 \mathrm{~N}+0,8 \mathrm{~S}, 200 \mathrm{~N}+0,4 \mathrm{~S}$ e $100 \mathrm{~N}$, respectivamente. Os tratamentos com $300 \mathrm{~N}+0,8 \mathrm{~S}$ e $200 \mathrm{~N}+0,4 \mathrm{~S}$ proporcionaram GPV de 44,9 e 37,0\% superiores em relação ao tratamento sem suplementação $(100 \mathrm{~N})$, em razão da maior lotação utilizada nesses tratamentos. Assmann et al. (1999) observaram incremento de $25 \%$ na produção por unidade de área ao utilizarem novilhos sob suplementação com milho em pastagem cultivada quando comparado àqueles sem suplementação, os quais não apresentaram diferença entre os níveis de 0,5 e 1,0\% do PV/dia. A média de produção obtida naquele trabalho foi de aproximadamente $800 \mathrm{~kg} / \mathrm{ha} \mathrm{de}$ PV. No entanto, Frizzo et al. (2003) relataram incrementos de 32,7 e $58,2 \%$ na produtividade animal para os níveis de 0,7 e $1,4 \%$ do PV/dia em relação ao tratamento sem suplementação, o qual resultou em ganho de $424,2 \mathrm{~kg} / \mathrm{ha}$ de PV.

\section{Conclusões}

Em pastagem de azevém anual em várzea, o teor de $\mathrm{PB}$ e a digestibilidade in vitro da matéria orgânica da forragem não são afetados pelas doses de nitrogênio.

As doses de nitrogênio em cobertura, associadas aos níveis de suplementação energética utilizados em pastagem de azevém, não alteram o ganho médio diário dos animais, mas proporcionam maior carga animal e, conseqüentemente, maior ganho de peso vivo por hectare.

\section{Literatura Citada}

ASSMANN, A.L.; ASSMANN, T.S.; MORAES, A. et al. Efeito de diferentes níveis de suplementação com milho no ganho de peso de novilhos em pastejo. In: REUNIÃO ANUAL DA SOCIEDADE BRASILEIRA DE ZOOTECNIA, 36., 1999, Porto Alegre. Anais... Porto Alegre: Sociedade Brasileira de Zootecnia, 1999. (CD-ROM)

ASSOCIATION OF OFFICIAL ANALYTICAL CHEMISTS - AOAC Official methods of analysis. 14.ed. Washington: 1984. 1141p.

BLASER, R.E. Symposium on forage utilization: effects of fertility levels and stage of maturity on forage nutritive value. Journal of Animal Science, v.23, p.246-253, 1964.

CANTO, M.W.; RESTLE, J.; QUADROS, F.L.F et al. Produção animal em pastagem de aveia (Avena strigosa Schreb) adubada com nitrogênio ou em mistura com ervilhaca (Vicia sativa L.). Revista Brasileira de Zootecnia, v.26, n.2, p.396-402, 1997.

COMISSÃO DE FERTILIDADE DO SOLO- RS/SC. Recomendação de adubação e de calagem para os estados do Rio Grande do Sul e de Santa Catarina. 3.ed. Pelotas: SBPS - Núcleo Regional Sul, 1999. 223p.

EMPRESA BRASILEIRA DE PESQUISA E AGROPECUÁRIA EMBRAPA. Centro Nacional de Pesquisa de Solos. Sistema brasileiro de classificação de solos. Rio de Janeiro: 1999. $412 \mathrm{p}$.

EUCLIDES, V.P.B; MACEDO, M.C.M.; OLIVEIRA, M.P. Avaliação de diferentes métodos de amostragem sob pastejo. Revista Brasileira de Zootecnia, v.21, n.4, p.691-702, 1992.

FRIZZO, A.; ROCHA, M.G.; RESTLE. J. et al. Suplementação energética na recria de bezerras de corte mantidas em pastagem de inverno. Revista Brasileira de Zootecnia, v.32, n.3, p.632-642, 2003.

GARDNER, A.L. Técnicas de pesquisa em pastagem e aplicabilidade de resultados em sistemas de produção. Brasília: EMBRAPA-CNPGL, 1986. 197p.

GIBB, M.J.; TREACHER, T.T. The effect of herbage allowance on herbage intake and performance of lambs grazing perennial 
ryegrass and red clover swards. Journal of Agricultural Science, v.86, p.355-365, 1976.

LUPATINI, G.C.; RESTlE, J.; CERETA, M. et al. Avaliação da mistura de aveia preta e azevém sob pastejo submetida a níveis de nitrogênio. Pesquisa Agropecuária Brasileira, v.33, n.11, p.1939-1943, 1998.

MARCHEZAN, E.; DIFANTE, G.S.; SEGABINAZZI, T. et al. Produção de novilhos de corte em área de várzea sistematizada, cultivada com mistura forrageira sob diferentes níveis de adubação. In: REUNIÃO ANUAL DA SOCIEDADE BRASILEIRA DE ZOOTECNIA, 37., 2000, Viçosa, MG. Anais... Viçosa, MG: Sociedade Brasileira de Zootecnia, 2000. (CD-ROM)

MORAES, A.; MOOJEN, E.L.; MARASCHIN, G.E. Comparação de métodos de estimativa de taxa de crescimento em uma pastagem submetida a diferentes pressões de pastejo. In: REUNIÃO DA SOCIEDADE BRASILEIRA DE ZOOTECNIA, 27., 1990, Campinas. Anais... Campinas: Fundação de Estudos Agrários Luiz de Queiroz, 1990. p.332.

PASCOAL, L.; BRONDANI, I. L.; BERNARDES, R. A. C. Avaliação de dietas para desmame, suplementação e confinamento. In: RESTLE, J. (Ed.) Confinamento, pastagens e suplementação para a produção de bovinos de corte. Santa Maria: Universidade Federal de Santa Maria, 1999. p.125-146.

REIS, J.C.L. Pastagens em terras baixas. Pelotas: EMBRAPACPACT, 1998. 35p (Circular Técnica, 7).

RESTle, J.; LUPATINI, G.C.; ROSO, C. et al. Eficiência e desempenho de categorias de bovinos de corte em pastagem cultivada. Revista Brasileira de Zootecnia, v.27, n.2, p.397-404, 1998.

RESTLE, J.; ROSO, C.; SOARES, A.B. et al. Produtividade animal e retorno econômico em pastagem de aveia preta mais azevém adubada com fontes de nitrogênio em cobertura. Revista Brasileira de Zootecnia, v.29, n.2, p.357-369, 2000.

ROCHA, M.G. Suplementação a campo de bovinos de corte. In: LOBATO, J.F.P.; BARCELOS, J.O.J.; KESSLER, A.M. (Eds.). Produção de bovinos de corte. Porto Alegre: EDI-PUCRS, 1999. p.77-96.

ROCHA, M.G.; RESTLE, J.; FARINATTI, L.H. et al. Efeito da suplementação energética sobre a produção animal em pastagem cultivada de inverno. In: REUNIÃO DA SOCIEDADE BRASILEIRA DE ZOOTECNIA, 37., 2000, Viçosa, MG. Anais... Viçosa, MG: Sociedade Brasileira de Zootecnia, 2000. (CD-ROM).
ROSO, C.; RESTLE, J.; SOARES, A.B. et al. Produção e qualidade de forragem da mistura de gramíneas anuais de estação fria sob pastejo contínuo. Revista Brasileira de Zootecnia, v.28, n.3, p.459-467, 1999.

SAIBRO, J.C.; SILVA, J.L.S. Integração sustentável do sistema arroz $\mathrm{x}$ pastagens utilizando misturas forrageiras de estação fria no litoral norte do Rio Grande do Sul. In: CICLO DE PALESTRAS EM PRODUÇÃO E MANEJO DE BOVINOS DE CORTE, 4. 1999, Canoas. Anais... Canoas: Universidade Luterana do Brasil, 1999. p.27-55

SANTINI, F.J.; ELIZALDE, J.C. Utilización de granos en la alimentacion de ruminantes. Revista Argentina de Producción Animal, v.3, n.1, p.39-60, 1993.

SILVA, J.L.S.; SAIBRO, J.C.; FREITAS, F.R. et al. Produtividade animal em diferentes pastagens de inverno em Planossolo no litoral norte do RS. In: REUNIÃO DA SOCIEDADE BRASILEIRA DE ZOOTECNIA, 34., 1997, Juiz de Fora. Anais... Juiz de Fora: Sociedade Brasileira de Zootecnia, 1997. p. 279-181.

STATISTICAL ANALYSES SYSTEM - SAS. User's guide. Version 6.08. Cary: 1990. 1014p.

TILLEY, J.M.A.; TERRY, R.A. A two-stage technique for "in vitro" digestion of forage crop. Journal Brithish Grassland Society, v. 18, n.2, p.104-111, 1963 .

WILM, H.G.; COSTELLO, D.F.; KLIPPLE, G.E. Estimating forage yield by the double-sampling methods. Journal American Society Agronomy, n.36, p.194-203, 1944.
Recebido: $13 / 08 / 04$ Aprovado: 07/02/06 